\title{
Subcutaneous Emphysema after a Dental Procedure
}

\author{
Daniela Brito, Catarina Medeiros, Lidia Caley \\ Centro Hospitalar do Médio Tejo, Portugal
}

Received: 30/12/2021

Accepted: $12 / 01 / 2022$

Published: 07/02/2022

How to cite this article: Brito D, Medeiros C, Caley L. Subcutaneous emphysema after a dental procedure. EJCRIM 2022;9: doi:10.12890/2022_003153.

Conflicts of Interests: The authors declare there are no competing interests.

This article is licensed under a Commons Attribution Non-Commercial 4.0 License

\section{ABSTRACT}

Subcutaneous emphysema is the presence of air beneath the skin's soft tissues. It can result from medical conditions, trauma or iatrogenic causes. The occurrence of subcutaneous emphysema after a dental procedure is rare. Although it is mostly a benign and self-limiting complication, the consequences may be severe and life-threatening. We report the case of a 20 -year-old man who presented to the emergency department with swelling of his face and neck after dental treatment. The diagnosis of subcutaneous emphysema and pneumomediastinum was made based on physical examination and a computerized tomography scan.

\section{LEARNING POINTS}

- Subcutaneous emphysema is a rare complication of dental procedures.

- It is mostly benign and self-limiting, although the consequences may be severe and potentially life-threatening.

- Early diagnosis and accurate treatment based on understanding its characteristics are important in the prognosis.

\section{KEYWORDS}

Subcutaneous emphysema, mediastinal emphysema, iatrogenic disease

\section{CASE DESCRIPTION}

A 20-year-old man with a history of gastritis medicated with a proton pump inhibitor, no history of smoking or previous drug allergies, developed acute swelling of the right side of the face after the extraction of the lower left wisdom tooth ( $\left.n^{\circ} 38\right)$. At the dental office, the initial suspicion was of a hypersensitivity reaction to lidocaine, and epinephrine $300 \mu \mathrm{g}$, hydrocortisone 200 mg and clemastine 2 mg were administered.

At arrival at the emergency department, the patient showed no signs of respiratory distress. Vital signs including heart rate, respiratory rate, oxygen saturation and blood pressure were in the normal range, and body temperature was $36.8^{\circ} \mathrm{C}$. The patient was alert and responsive. Physical examination showed swelling from the right infraorbital region to the submandibular regions with crepitus on palpation (Fig. 1). No alteration to the oral cavity was detected. Auscultation of the lungs and heart was normal. The rest of the physical examination was unremarkable.

A neck and chest computerized tomography (CT) scan was performed, showing 'extensive facial subcutaneous emphysema (mandibular and lateral maxillary, extending to the right orbital region) and the cervical region (submandibular, sublingual, anterior and posterior cervical left spaces, parotid, carotid, parapharyngeal and retropharyngeal spaces, extending to the superior mediastinum, posterior to the esophagus)' (Figs. 2 and 3), further supporting the diagnosis of cervicofacial emphysema and pneumomediastinum after a dental procedure. The treatment approach was discussed with cardiothoracic surgery, and clinical surveillance and antibiotic prophylaxis with amoxicillin/ clavulanic acid and metronidazole for 7 days was suggested. The swelling and crepitus subsided after 5 days, and no complications were noticed. A follow-up CT scan demonstrated overall improvement of subcutaneous emphysema. The patient was discharged and maintained follow-up in as a stomatology outpatient for extraction of other teeth. 


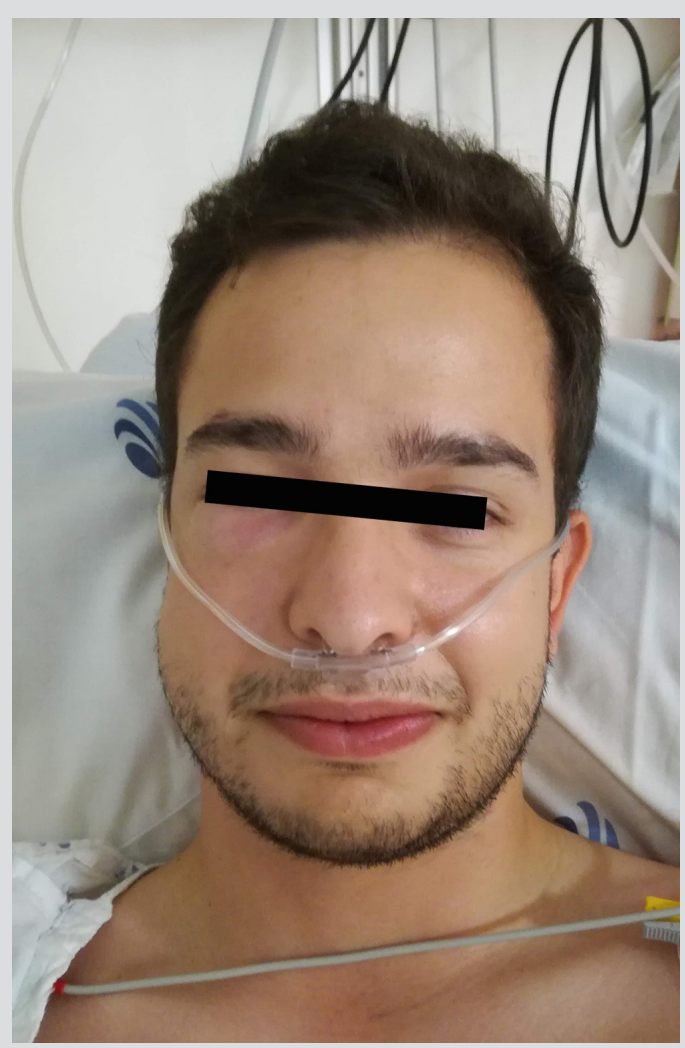

Figure 1. Neck and facial swelling with eyelid involvement

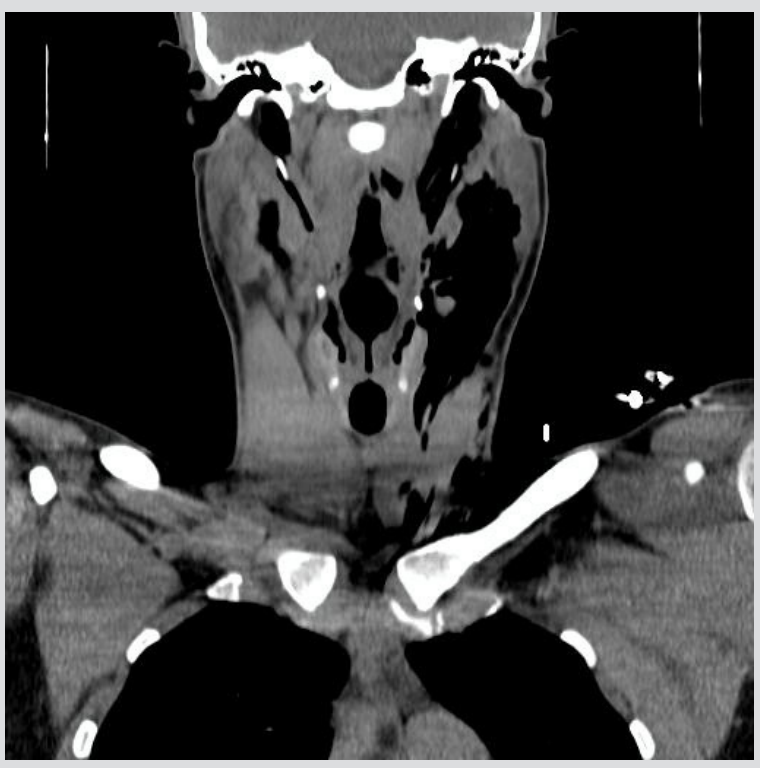

Figure 2. Coronal view of face and neck CT showing right-sided subcutaneous emphysema

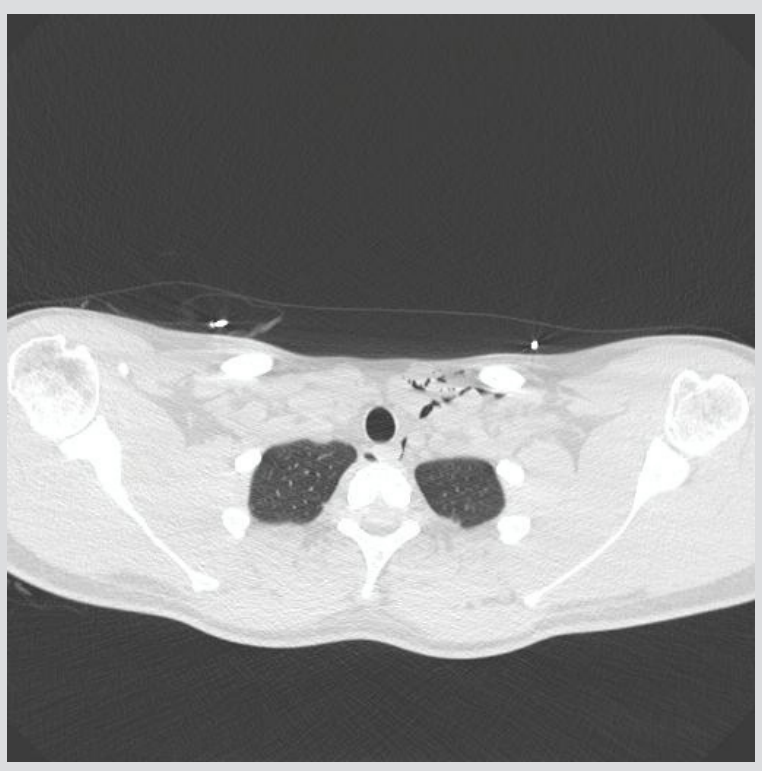

Figure 3. Axial view of chest CT showing mediastinal emphysema

\section{DISCUSSION}

Subcutaneous emphysema (SE) occurs due to the presence of air beneath soft tissues, which can lead to dissection of the fascial planes in the affected areas ${ }^{[1]}$. SE can have several aetiologies: it can result from blunt trauma, medical conditions such as infection and asthma, or iatrogenic causes, which include laparoscopic procedures, mechanical ventilation, gastric tube placement, and dental procedures ${ }^{[1-4]}$.

The occurrence of SE as a complication of dental treatment is rare, especially when the treatment is non-surgical ${ }^{[2]}$. This complication was 
first documented in 1900; since then the majority of cases are associated with the use of air-driven high-speed handpieces and air syringes ${ }^{[3}$. 5]. It occurs because the roots of the lower molar teeth are anatomically related to the sublingual, submandibular and buccal spaces. When air is introduced, it travels along the path of least resistance to involve the related infraorbital, cervical, lateral pharyngeal and retropharyngeal spaces $^{[2,3,5]}$, which was the case in our patient.

The presentation of emphysema can be immediate or be delayed by several hours/days after the intervention ${ }^{[2,6]}$. The differential diagnosis with other entities, such as hypersensitivity reaction, haematoma, infection and angioedema, is very important, and physical examination is key. The presence of crepitus at palpation of the neck and face is pathognomonic for SE ${ }^{[1-6]}$. Other characteristics may be absent, such as systemic symptoms ${ }^{[3,5,6]}$. In case of pneumomediastinum, Hamman's sign can be presented at auscultation ${ }^{[2,3]}$. Radiolucent air layers may be observed on the plain $\mathrm{x}$-ray of the neck, while on CT scan, multiple radiolucent bubble-like images can be documented ${ }^{[7]}$.

Although this complication is mostly benign and self-limiting, the consequences can be severe and potentially life-threatening ${ }^{[2,3]}$. Some situations like tension pneumothorax, air emboli and blindness have been reported previously ${ }^{[5,6]}$. When the retropharyngeal space is involved, tracheal compression may occur ${ }^{[3]}$. Some oral bacteria can be introduced along the emphysematous tracts, so complications like mediastinitis and necrotizing fasciitis may develop ${ }^{[3,4,7]}$.

The use of prophylactic antibiotics and corticosteroids may be considered, and has been reported in the literature, however there is no consensus ${ }^{[6]}$. Oxygen administration can also be considered because it replaces the air and is more rapidly reabsorbed, which can be beneficial $^{[3,4,7]}$.

The emphysema usually resolves within $3-10$ days ${ }^{[5,6]}$, without follow-up required.

In conclusion, this is a rare and usually benign complication, in which prompt diagnosis is necessary for treatment and management.

\section{REFERENCES}

1. Gamboa-Vidal C, Vega-Pizarro C, Almeida-Arriagada A. Subcutaneous emphysema secondary to dental treatment. Med Oral Patol Oral Cir Bucal 2007;12:76-78.

2. Rad MV, Chan EKY, Ahmed IH. Cervicofacial subcutaneous emphysema and pneumomediastinum secondary to dental treatment in a young man. Respir Med Case Rep 2019 Jul 31;28:100918.

3. Mascarenhas RJ. Management of subcutaneous facial emphysema secondary to a class V dental restoration. Clin Case Rep 2019 May 1;7(5):1025-1030.

4. Frühauf J, Weinke R, Pilger U, Kerl H, Müllegger RR. Soft tissue cervicofacial emphysema after dental treatment: report of 2 cases with emphasis on the differential diagnosis of angioedema. Arch Dermatol Nov 2005;141(11):1437-1440.

5. Gomes I. Enfisema subcutâneo cervicofacial após dentisteria operatória: caso clínico. Rev Port Estomatol Med Dent Cir Maxilofac 2011 Jul;52(3):153-156.

6. Wong P, Palacios S, Kashtwari D. Managing subcutaneous emphysema following dental procedures. Decisions in Dentistry 2017;3(9):36, 39-41. Available from: https:// decisionsindentistry.com/article/managing-subcutaneous-emphysema-following-dental-procedures/

7. Jeong CH, Yoon S, Chung SW, Kim JY, Park KH, Huh JK. Subcutaneous emphysema related to dental procedures. J Korean Assoc Oral Maxillofac Surg 2018;44(5):212-219. 